\title{
Vertex and edge Co-PI indices of bridge graphs
}

\author{
Sharmila devi.G ${ }^{1 *}$ and Kaladevi. $V^{2}$ \\ ${ }^{1}$ Research Scholar, Research and Development Centre, Bharathiar University, Coimbatore. Department of Mathematics, Kongu Arts and \\ Science college(Autonomous), Erode, India. \\ ${ }^{2}$ Department of Mathematics, Bishop Heber College, Trichy, India \\ *Corresponding author E-mail:sharmilashamritha@gmail.com
}

\begin{abstract}
The Co-PI index of a graph $G$, denoted by $C o-P I(G)$, is defined as $C o-P I(G)=\sum_{u v=e \in E(G)}\left|n_{u}^{G}(e)-n_{v}^{G}(e)\right|$, where $n_{u}^{G}(e)$ is number of vertices of $G$ whose distance to the vertex $u$ is less than the distance to the vertex $v$ in $G$. Similarly, the edge Co-PI index of $G$ is defined as $C o-P I_{e}(G)=\sum_{u v=e \in E(G)}\left|m_{u}^{G}(e)-m_{v}^{G}(e)\right|$, where $m_{u}^{G}(e)$ is number of edges of $G$ whose distance to the vertex $u$ is less than the distance to the vertex $v$ in $G$. In this paper, the upperbound for the Co-PI and edge Co-PI indices of bridge graph are obtained.
\end{abstract}

Keywords: Bridge Graph; Co-PI Index; Edge Co-PI Index.

\section{Introduction}

All the graphs considered in this paper are connected and simple.A vertex $x \in V(G)$ is said to be equidistant from the edge $e=u v$ of $G$ if $d_{G}(u, x)=d_{G}(v, x)$, where $d_{G}(u, x)$ denotes the distance between $u$ and $x$ in $G$. The degree of the vertex $u$ in $G$ is denoted by $d_{G}(u)$. The edges $e=u v$ and $f=x y$ of $G$ are said to be equidistant edges if $\min \left\{d_{G}(u, x), d_{G}(u, y)\right\}=\min \left\{d_{G}(v, x), d_{G}(v, y)\right\}$.

For an edge $u v=e \in E(G)$, the number of vertices of $G$ whose distance to the vertex $u$ is smaller than the distance to the vertex $v$ in $G$ is denoted by $n_{u}^{G}(e)$; analogously, $n_{v}^{G}(e)$ is the number of vertices of $G$ whose distance to the vertex $v$ in $G$ is smaller than the distance to the vertex $u$; the vertices equidistant from both the ends of the edge $e=u v$ are not counted. Similarly, $m_{u}(e)$ denotes the number of edges of $G$ whose distance to the vertex $u$ is less than the distance to the vertex $v$.

The vertex PI index of $G$, denoted by $P I(G)$, is defined as $P I(G)=\sum_{e=u v \in E(G)}\left(n_{u}^{G}(e)+n_{v}^{G}(e)\right)$ and

the edge PI index of $G$, denoted by $P I_{e}(G)$, is defined as $P I_{e}(G)=\sum_{e=u v \in E(G)}\left(m_{u}^{G}(e)+m_{v}^{G}(e)\right)$.

Similarly, the Co-PI index of $G$, denoted by $\operatorname{Co} P I(G)$, is defined as $C o-P I(G)=\sum_{e=u v \in E(G)}\left|n_{u}^{G}(e)-n_{v}^{G}(e)\right|$ and

the edge Co-PI index of $G$, denoted by $C o-P I_{e}(G)$, is defined as $C o-P I_{e}(G)=\sum_{e=u v \in E(G)}\left|m_{u}^{G}(e)-m_{v}^{G}(e)\right|$.

Khadikar [12] first introduced edge PI index of graphs and they investigated the chemical applications of the PI index. The PI index of the graph $G$ is a topological index related to equidistant vertices. Another topological index of $G$ related to distance of $G$ is the wiener index of $G$, first introduced by wiener, see[18]. Khadikar,
Karmarkar and Agarwal [12] first introduced edge Padmakar-Ivan index of graphs and they investigated the chemical applications of the Padmakar-Ivan index. The mathematical properties of the $P I_{v}$ and its applications in chemistry and nanoscience are well studied by Ashrafi and Loghman [1,3]. Ashrafi and Rezari [2], Deng, Chen and Zhang [6], Khadikar [10], Khalifeh, Yousefi-Azari and Ashrafi [11], Klavžar [13] and Yousefi-Azari, Manoochehrian and Ashrafi [17]. The vertex PI indices of the tensor and strong products of graphs are studied in $[14,16]$. In $[20,21,22]$ the PI indices of bridge graphs and chain graphs are discussed. In this paper, the upper bounds for the Co-PI and edge Co-PI indices of bridge graphs are obtained. Let $\left\{G_{i}\right\}_{i=1}^{s}$ be a set of finite pairwise vertex disjoint connected graphs with $v_{i} \in V\left(G_{i}\right)$. The bridge graph $B\left(G_{1}, G_{2}, \ldots, G_{s}\right)=B\left(G_{1}, G_{2}, \ldots, G_{s} ; v_{1}, v_{2}, \ldots, v_{s}\right)$ of $\left\{G_{i}\right\}_{i=1}^{s}$ with respect to the vertices $\left\{v_{i}\right\}_{i=1}^{s}$ is the graph obtained from the graphs $G_{1}, G_{2}, \ldots, G_{s}$ by connecting the vertices $v_{i}$ and $v_{i+1}$ by an edge for all $i=1,2, \ldots, s-1$.

\section{Co-PI Index of Bridge Graph}

Let $G$ be a graph and let $v \in V(G)$. The set of all edges $x y$ such that $d_{G}(x, v)=d_{G}(y, v)$ is denoted by $N_{v}(G)$. Define $K\left(G_{i}\right)=\{e=x y \in$ $\left.E\left(G_{i}\right) \backslash N_{v} \mid d(x, v)<d(y, v)\right\}$ and

$L\left(G_{i}\right)=\left\{e=x y \in E\left(G_{i}\right) \backslash N_{v} \mid d(x, v)>d(y, v)\right\}$.

Theorem 2.1

Let $G=B\left(G_{1}, G_{2}, \ldots, G_{s}\right)$ of $\left\{G_{i}\right\}_{i=1}^{s}$ with respect to the vertices $\left\{v_{i}\right\}_{i=1}^{s}$ and $|V(G)|=a$. Then $\operatorname{Co}-\operatorname{PI}(G) \leq \sum_{i=1}^{s}(C o-$ $\left.P I\left(G_{i}\right)\right)+\sum_{i=1}^{s}\left(|V(G)|-\left|V\left(G_{i}\right)\right|\right)\left(k_{i}+\ell_{i}\right)+\sum_{i=1}^{s-1}\left(2 a_{i}-a\right)$, where $a_{i}=\sum_{j=1}^{i}\left|V\left(G_{j}\right)\right|, k_{i}=\left|E\left(K\left(G_{i}\right)\right)\right|$ and $l_{i}=\left|E\left(L\left(G_{i}\right)\right)\right|$ 
Proof. From the definition of $C o-P I(G)$,

$$
\begin{aligned}
C o-P I(G)= & \sum_{e=u v \in E(G)}\left|n_{u}^{G}(e)-n_{v}^{G}(e)\right| \\
= & \sum_{i=1}^{s} \sum_{e=u v \in E\left(G_{i}\right)}\left|n_{u}^{G}(e)-n_{v}^{G}(e)\right| \\
& +\sum_{i=1}^{s-1}\left|n_{v_{i}}^{G}\left(v_{i} v_{i+1}\right)-n_{v_{i+1}}^{G}\left(v_{i} v_{i+1}\right)\right| \\
= & \sum_{i=1}^{s} \sum_{e=u v \in N_{v_{i}}\left(G_{i}\right)}\left|n_{u}^{G}(e)-n_{v}^{G}(e)\right| \\
& +\sum_{i=1}^{s} \sum_{e=u v \in E\left(G_{i}\right) \backslash N_{v_{i}}\left(G_{i}\right)}\left|n_{u}^{G}(e)-n_{v}^{G}(e)\right| \\
& +\sum_{i=1}^{s-1}\left|n_{v_{i}}^{G}\left(v_{i} v_{i+1}\right)-n_{v_{i+1}}^{G}\left(v_{i} v_{i+1}\right)\right| .
\end{aligned}
$$

The summations in equation (1) are computed separately. Case (A):

If $e=u v \in N_{v_{i}}\left(G_{i}\right)$, then all the vertices in $V(G) \backslash V\left(G_{i}\right)$ are equidistant from the ends of the edge $e=u v$. This implies $n_{u}^{G}(e)=n_{u}^{G_{i}}(e)$ and $n_{v}^{G}(e)=n_{v}^{G_{i}}(e)$. Then

$$
\sum_{e=u v \in N_{v_{i}}\left(G_{i}\right)}\left|n_{u}^{G}(e)-n_{v}^{G}(e)\right|=\sum_{e=u v \in N_{v_{i}}\left(G_{i}\right)}\left|n_{u}^{G_{i}}(e)-n_{v}^{G_{i}}(e)\right| .
$$

Thus $\quad \sum_{i=1}^{s} \sum_{e=u v \in N_{v_{i}}\left(G_{i}\right)}\left|n_{u}^{G}(e)-n_{v}^{G}(e)\right|$

$\sum_{i=1}^{s} \sum_{e=u v \in N_{v_{i}}\left(G_{i}\right)}\left|n_{u}^{G_{i}}(e)-n_{v}^{G_{i}}(e)\right|$.

Case (B):

If $e=u v \in E\left(G_{i}\right) \backslash N_{v_{i}}\left(G_{i}\right)$ then, the following cases are arise:

(i) If $e=u v \in K\left(G_{i}\right)$, then

$$
\begin{aligned}
n_{u}^{G}(e)-n_{v}^{G}(e) & =n_{u}^{G_{i}}(e)+|V(G)|-\left|V\left(G_{i}\right)\right|-n_{v}^{G_{i}}(e) \\
& =n_{u}^{G_{i}}(e)-n_{v}^{G_{i}}(e)+|V(G)|-\left|V\left(G_{i}\right)\right| .
\end{aligned}
$$

(ii) If $e=u v \in L\left(G_{i}\right)$, then

$$
\begin{aligned}
n_{u}^{G}(e)-n_{v}^{G}(e) & =n_{u}^{G_{i}}(e)-\left(n_{v}^{G_{i}}(e)+|V(G)|-\left|V\left(G_{i}\right)\right|\right) \\
& =n_{u}^{G_{i}}(e)-n_{v}^{G_{i}}(e)-\left(|V(G)|-\left|V\left(G_{i}\right)\right|\right) .
\end{aligned}
$$

$$
\begin{aligned}
\text { Thus, } & \sum_{e=u v \in E\left(G_{i}\right) \backslash N_{v_{i}}\left(G_{i}\right)}\left|n_{u}^{G}(e)-n_{v}^{G}(e)\right| \\
= & \sum_{e=u v \in K\left(G_{i}\right)}\left|n_{u}^{G}(e)-n_{v}^{G}(e)\right|+\sum_{e=u v \in L\left(G_{i}\right)}\left|n_{u}^{G}(e)-n_{v}^{G}(e)\right| \\
\leq & \sum_{e=u v \in E\left(G_{i}\right) \backslash N_{v_{i}}\left(G_{i}\right)}\left|n_{u}^{G_{i}}(e)-n_{v}^{G_{i}}(e)\right| \\
+ & \sum_{e=u v \in K\left(G_{i}\right)}\left|\left(|V(G)|-\left|V\left(G_{i}\right)\right|\right)\right| \\
+ & \sum_{e=u v \in L\left(G_{i}\right)}\left|\left(|V(G)|-\left|V\left(G_{i}\right)\right|\right)\right|
\end{aligned}
$$

Case (C):

If $e$ is an edge $e=v_{i} v_{i+1}$, then there exists no vertex $t$ which is equidistant from the ends of the edge $e$. Since $n_{v_{i}}^{G}(e)-n_{v_{i+1}}^{G}(e)=$ $\sum_{j=1}^{i}\left|V\left(G_{j}\right)\right|-\sum_{j=i+1}^{s}\left|V\left(G_{j}\right)\right|=a_{i}-\left(|V(G)|-a_{i}\right)=2 a_{i}-|V(G)|$, the last summation in (1) becomes

$$
\begin{gathered}
\sum_{i=1}^{s-1}\left|n_{v_{i}}^{G}\left(v_{i} v_{i+1}\right)-n_{v_{i+1}}^{G}\left(v_{i} v_{i+1}\right)\right|=\sum_{i=1}^{s-1}\left|\sum_{j=1}^{i}\right| V\left(G_{j}\right)\left|-\sum_{j=i+1}^{s}\right| V\left(G_{j}\right)|| \\
\leq \sum_{i=1}^{s-1}\left(2 a_{i}-|V(G)|\right)
\end{gathered}
$$

$$
\begin{aligned}
\text { Hence, } C o-P I(G)= & \sum_{i=1}^{s} \sum_{e=u v \in N_{v_{i}}\left(G_{i}\right)}\left|n_{u}^{G_{i}}(e)-n_{v}^{G_{i}}(e)\right| \\
& +\sum_{e=u v \in E\left(G_{i}\right) \backslash N_{v_{i}}\left(G_{i}\right)}\left|n_{u}^{G_{i}}(e)-n_{v}^{G_{i}}(e)\right| \\
& +\sum_{e=u v \in K\left(G_{i}\right)}\left|\left(|V(G)|-\left|V\left(G_{i}\right)\right|\right)\right| \\
& +\sum_{e=u v \in L\left(G_{i}\right)}\left|\left(|V(G)|-\left|V\left(G_{i}\right)\right|\right)\right| \\
& +\sum_{i=1}^{s-1}\left(2 a_{i}-|V(G)|\right) \\
\leq & \sum_{i=1}^{s}\left(C o-P I\left(G_{i}\right)\right)+\sum_{i=1}^{s}\left(|V(G)|-\left|V\left(G_{i}\right)\right|\right)\left(k_{i}+\ell_{i}\right) \\
& +\sum_{i=1}^{s-1}\left(2 a_{i}-|V(G)|\right) .
\end{aligned}
$$

\section{Edge Co-PI Index of Bridge Graph}

For a graph $G$ with $v \in V(G)$, let $T_{v}(G)$ be the set of edges $u v$ of $G$ such that $d_{G}(x, v)=d_{G}(x, u)$. For a bridge graph $B\left(G_{1}, G_{2}, \ldots, G_{s}\right)$, $i=1,2, \ldots, s-1$, let $K\left(G_{i}\right)$ be the set of edges $e=x y \in E\left(G_{i}\right) \backslash$ $T_{v_{i}}\left(G_{i}\right)$ such that $d_{G}\left(x, v_{i}\right)<d_{G}\left(y, v_{i}\right)$ and $L\left(G_{i}\right)$ the set of edges $e=u v \in E\left(G_{i}\right) \backslash T_{v_{i}}\left(G_{i}\right)$ such that $d_{G}\left(x, v_{i}\right)>d_{G}\left(y, v_{i}\right)$.

\section{Theorem 3.1}

Let $G=B\left(G_{1}, G_{2}, \ldots, G_{s}\right)$ of $\left\{G_{i}\right\}_{i=1}^{s}$ with respect to the vertices $\left\{v_{i}\right\}_{i=1}^{s}$. Then $C o-P I_{e}(G) \leq \sum_{i=1}^{s}\left(C o-P I_{e}\left(G_{i}\right)\right)+$ $\sum_{i=1}^{s}\left(|E(G)|-\left|E\left(G_{i}\right)\right|\right)\left(k_{i}+\ell_{i}\right)+\sum_{i=1}^{s-1}\left(2 a_{i}-\left|E\left(G_{j}\right)\right|+1\right)$, where $a_{i}=\sum_{j=1}^{i}\left|E\left(G_{j}\right)\right|+i-1, k_{i}=\left|E\left(K\left(G_{i}\right)\right)\right|$ and $l_{i}=\left|E\left(L\left(G_{i}\right)\right)\right|$.

Proof. Let $G=B\left(G_{1}, G_{2}, \ldots, G_{s}\right)$. Observe that $E\left(G_{i}\right)=T_{v_{i}}\left(G_{i}\right) \cup$ $K\left(G_{i}\right) \cup L\left(G_{i}\right)$ for $i=1,2, \ldots, s$. By the definition of the edge Co-PI index,

$$
\begin{aligned}
C o-P I_{e}(G)= & \sum_{e=u v \in E(G)}\left|m_{u}^{G}(e)-m_{v}^{G}(e)\right| \\
= & \sum_{i=1}^{s} \sum_{e=u v \in T_{v_{i}}\left(G_{i}\right)}\left|m_{u}^{G}(e)-m_{v}^{G}(e)\right| \\
& +\sum_{i=1}^{s} \sum_{e=u v \in K\left(G_{i}\right) \cup L\left(G_{i}\right)}\left|m_{u}^{G}(e)-m_{v}^{G}(e)\right| \\
& +\sum_{i=1}^{s-1}\left|m_{v_{i}}^{G}\left(v_{i} v_{i+1}\right)-m_{v_{i+1}}^{G}\left(v_{i} v_{i+1}\right)\right| .
\end{aligned}
$$

- For $i=1,2, \ldots, s$, if $e=u v \in T_{v_{i}}\left(G_{i}\right)$, then $d_{G}\left(v_{i}, u\right)=$ $d_{G}\left(v_{i}, v\right)$, and for any edge $e_{1} \in E(G) \backslash E\left(G_{i}\right)$, then $d_{G}\left(u, e_{1}\right)=$ $d_{G}\left(v, e_{1}\right)$. This implies $m_{u}^{G}(e)=m_{u}^{G_{i}}(e)$ and $m_{v}^{G}(e)=m_{v}^{G_{i}}(e)$. Then $\sum_{e=u v \in T_{v_{i}}\left(G_{i}\right)}\left|m_{u}^{G}(e)-m_{v}^{G}(e)\right|=\sum_{e=u v \in T_{v_{i}}\left(G_{i}\right)}\left|m_{u}^{G_{i}}(e)-m_{v}^{G_{i}}(e)\right|$.

- For $i=1,2, \ldots, s$, if $e=u v \in K\left(G_{i}\right)$, then $d_{G}\left(v_{i}, u\right)<d_{G}\left(v_{i}, v\right)$, thus

$$
\begin{aligned}
m_{u}^{G}(e)-m_{v}^{G}(e) & =m_{u}^{G_{i}}(e)+s-1+\sum_{1 \leq j \leq s, j \neq i}\left|E\left(G_{j}\right)\right|-m_{v}^{G_{i}}(e) \\
& =m_{u}^{G_{i}}(e)-m_{v}^{G_{i}}(e)+\left(|E(G)|-\left|E\left(G_{i}\right)\right|\right)
\end{aligned}
$$

Similarly, if $e=u v \in L\left(G_{i}\right)$, then $d_{G}\left(v_{i}, u\right)>d_{G}\left(v_{i}, v\right)$, thus

$m_{u}^{G}(e)-m_{v}^{G}(e)=m_{u}^{G_{i}}(e)-\left(m_{v}^{G_{i}}(e)+s-1+\sum_{1 \leq j \leq s, j \neq i}\left|E\left(G_{j}\right)\right|\right)$

$$
=m_{u}^{G_{i}}(e)-m_{v}^{G_{i}}(e)-\left(|E(G)|-\left|E\left(G_{i}\right)\right|\right) .
$$




$$
\begin{aligned}
e=u v \in K\left(G_{i}\right) \cup L\left(G_{i}\right) & \left|m_{u}^{G}(e)-m_{v}^{G}(e)\right| \\
= & \sum_{e=u v \in K\left(G_{i}\right)}\left|m_{u}^{G}(e)-m_{v}^{G}(e)\right|+\sum_{e=u v \in L\left(G_{i}\right)}\left|m_{u}^{G}(e)-m_{v}^{G}(e)\right| \\
= & \sum_{e=u v \in K\left(G_{i}\right)}\left|m_{u}^{G_{i}}(e)-m_{v}^{G_{i}}(e)+\left(|E(G)|-\left|E\left(G_{i}\right)\right|\right)\right| \\
& +\sum_{e=u v \in L\left(G_{i}\right)}\left|m_{u}^{G_{i}}(e)-m_{v}^{G_{i}}(e)-\left(|E(G)|-\left|E\left(G_{i}\right)\right|\right)\right| \\
\leq & \sum_{e=u v \in K\left(G_{i}\right)}\left|m_{u}^{G_{i}}(e)-m_{v}^{G_{i}}(e)\right|+\sum_{e=u v \in K\left(G_{i}\right)}\left(|E(G)|-\left|E\left(G_{i}\right)\right|\right) \\
& +\sum_{e=u v \in L\left(G_{i}\right)}\left|m_{u}^{G_{i}}(e)-m_{v}^{G_{i}}(e)\right|+\sum_{e=u v \in L\left(G_{i}\right)}\left(|E(G)|-\left|E\left(G_{i}\right)\right|\right) .
\end{aligned}
$$

- For an edge $e=v_{i} v_{i+1}, \quad i=1,2, \ldots, s-1$, one can easily observe that $m_{v_{i}}^{G}(e)-m_{v_{i+1}}^{G}(e)=\left(\sum_{j=1}^{i}\left|E\left(G_{j}\right)\right|+i-1\right)-$

$$
\begin{aligned}
& \left(\sum_{j=i+1}^{s}\left|E\left(G_{j}\right)\right|+s-(i+1)\right) . \\
& \sum_{i=1}^{s-1}\left|m_{v_{i}}^{G}\left(v_{i} v_{i+1}\right)-m_{v_{i+1}}^{G}\left(v_{i} v_{i+1}\right)\right| \\
& =\sum_{i=1}^{s-1}\left|\left(\sum_{j=1}^{i}\left|E\left(G_{j}\right)\right|+i-1\right)-\left(\sum_{j=i+1}^{s}\left|E\left(G_{j}\right)\right|+s-(i+1)\right)\right| \\
& =\sum_{i=1}^{s-1}\left|a_{i}-\left(\left|E\left(G_{j}\right)\right|-1-a_{i}\right)\right| \\
& \leq \sum_{i=1}^{s-1}\left(2 a_{i}-\left|E\left(G_{j}\right)\right|+1\right) .
\end{aligned}
$$

Hence the edge Co-PI index of the bridge graph is given by,

$$
\begin{aligned}
& C o-P I_{e}(G)=\sum_{i=1}^{s} \sum_{e=u v \in T_{v_{i}}\left(G_{i}\right)}\left|m_{u}^{G_{i}}(e)-m_{v}^{G_{i}}(e)\right| \\
& +\sum_{i=1}^{s} \sum_{e=u v \in K\left(G_{i}\right)}\left|m_{u}^{G_{i}}(e)-m_{v}^{G_{i}}(e)\right| \\
& +\sum_{i=1}^{s} \sum_{e=u v \in K\left(G_{i}\right)}\left(|E(G)|-\left|E\left(G_{i}\right)\right|\right) \\
& +\sum_{i=1}^{s} \sum_{e=u v \in L\left(G_{i}\right)}\left|m_{u}^{G_{i}}(e)-m_{v}^{G_{i}}(e)\right| \\
& +\sum_{i=1}^{s} \sum_{e=u v \in L\left(G_{i}\right)}\left(|E(G)|-\left|E\left(G_{i}\right)\right|\right)+\sum_{i=1}^{s-1}\left(2 a_{i}-\left|E\left(G_{j}\right)\right|+1\right) \\
& =\sum_{i=1}^{s} C o-P I_{e}\left(G_{i}\right)+\sum_{i=1}^{s}\left(|E(G)|-\left|E\left(G_{i}\right)\right|\right)\left(k_{i}+\ell_{i}\right) \\
& +\sum_{i=1}^{s-1}\left(2 a_{i}-\left|E\left(G_{j}\right)\right|+1\right) .
\end{aligned}
$$

\section{References}

[1] Ashrafi A.R., Loghman A., PI index of zig-zag polyhex nanotubes, MATCH Commun. Math. Comput. Chem. 55(2006) 447-452.

[2] Ashrafi A.R., Rezaei F., PI index of polyhex nanotori, MATCH Commun. Math. Comput. Chem. 57(2007) 243-250.

[3] Ashrafi A.R., Loghman A., PI index of armchair polyhex nanotubes, Ars Combin. 80(2006) 193-199.

[4] Barriere L., Comellas F., Dalfo C and Fiol M A., The hierarchical product of graphs, Discrete Appl. Math. 157(2009) 36-48.

[5] Barriere L., Dalfo C., Fiol M A., and Mitjana., The generalized hierarehical product of graphs, Discrete Math. 309(2009) 3871-3881.

[6] Deng H., Chen S., Zhang J., The PI index of phenylenes, J. Math. Chem. 41(2007) 63-69.
[7] Eliasi M., Iranmanesh A., The hyper-Wiener index of the generalized hierarchical product of graphs, Discrete Appl. Math. 159(2011) 866 871

[8] Hoji M., Luo Z., Vumar E., Wiener and vertex PI indices of Kronecker products of graphs, Discrete Appl. Math. 158 (2010) 1848-1855.

[9] Khalifeh M H., Yousefi Azari H and Ashrafi A R., Vertex and edge PI indices of cartesian product graphs, Discrete Appl. Math. 156(2008) 1780-1789.

[10] Khadikar P.V., On a novel structural descriptor PI, Nat. Acad. Sci. Lett. 23(2000) 113-118.

[11] Khalifeh M.H., Yousefi-Azari H., Ashrafi A.R., The hyper-Wiener index of graph operations, Comput. Math. Appl. 56(2008) 1402 - 1407.

[12] Khadikar P.V., Karmarkar S., Agrawal V.K., A novel PI index and its application to QSPR/QSAR studies, J. Chem. Inf. Comput. Sci. 41(2001) 934-949.

[13] Klavžar S., On the PI index: PI-partitions and Cartesian product graphs, MATCH Commun. Math. Comput. Chem. 57(2007) 573-586.

[14] Pattabiraman K., Paulraja P., On some topological indices of the tensor products of graphs, Discrete Appl. Math. 160(2012) 267-279.

[15] Pattabiraman K., Paulraja P., Vertex and edge padmakar Ivan indices of generalized hierarchical product of graphs, Discrete Appl. Math 160(2012), 1376-1384.

[16] Pattabiraman K., Paulraja P., Wiener and vertex PI indices of the strong product of graphs, Discuss. Math. Graph Theory 32(2012) 749769

[17] Yousefi-Azari H., Manoochehrian B., Ashrafi A.R., The PI index of product graphs, Appl. Math. Lett. 21(2008) 624-627.

[18] Wiener H., Structural determination of the paraffin boiling points, $J$. Am. Chem. Soc. 69(1947) 17-20.

[19] Ilic A and Milosavljevic N., The weighted vertex PI index, Math. Comput. Model. 57 623-631.

[20] Mansour T., Schork M., The PI index of bridge and chain graphs, MATCH Commun. Math. Comput. Chem. 61:3(2009) 723-734.

[21] Mansour T., Schork M., The vertex PI index and Szeged index of bridge graphs, Discrete Appl. Math. 157(2009) 1600-1606.

[22] Mansour T., Schork M., The PI Index of Polyomino Chains of $4 k-$ Cycles, Acta Appl. Math. 109(2010) 671-681. 